\title{
Identifying the role of human resource management in increasing performance and implementation of six sigma projects using fuzzy cognitive maps
}

\author{
Seyyed Yousef Oleyaei-Motlagh ${ }^{a^{*}}$ and Ali Bonyadi-Naeini ${ }^{b}$
}

${ }^{a}$ Young Researchers and Elites Club, North Tehran Branch, Islamic Azad University, Tehran, Iran

${ }^{b}$ Department of Industrial Engineering, Iran University of Science and Technology (IUST), Narmak, Tehran 16846-13114, Iran

C H R O N I C L E

Article history:

Received December 10, 2013

Received in revised format

12 March 2013

Accepted April 142014

Available online

April 162014

Keywords:

Human Resources Management

Six Sigma

Fuzzy Cognitive Maps

Project Management

\section{A B S T R A C T}

Six Sigma is known as the best quality management system, which has been applied in different places with distinct tasks. Any implementation of Six Sigma project normally can succeed only when human resource management is applied within the organization, properly. In this paper, we illustrate the intense of relationships between the human resources management indices and Six Sigma project implementation indices for some selected Iranian manufacturing firms. By using the fuzzy cognitive maps (FCM), we are able to show the strength of relationships among various indices. This study helps quality and human resource managers learn how to manage the critical indices to achieve their determined goals and to increase Six Sigma project performance throw human resource management perspective.

\section{Introduction}

Human resource management is one of the most essential sources for business development. There are different definitions for human resource management (HRM). According to Armstrong (2003), HRM is a strategic and coherent approach to the management of an organization's most valued assets; the people working there whom individually and collectively contribute to the achievement of its objectives (Armstrong 2003). Storey (1989) believes that HRM could be regarded as a 'set of interrelated policies with an ideological and philosophical underpinning'. He suggests four aspects that constitute the meaningful version of HRM:

1. A particular constellation of beliefs and assumptions,

2. A strategic thrust informing decisions about people management,

3. The central involvement of line managers,

4. Reliance upon a set of 'levers' to shape the employment relationship.

* Corresponding author. Tel: +984116585628

E-mail addresses: yousef.oliaee@iustn.ac.ir (S. Y. Oleyaei-Motlagh)

(C) 2014 Growing Science Ltd. All rights reserved.

doi: $10.5267 /$ j.uscm.2014.4.002 
Many of the well-known firms, such as Motorola, General Electric, Honeywell, Raytheon, Sony, Caterpillar, and Johnson Controls, have successfully applied Six Sigma and reported remarkable improvements in market share, customer satisfaction, reliability, and performance of products and services with remarkable financial savings (Foster, 2007; Harry \& Schroeder 2000; Pande \& Holp, 2002; Snee, 1999). Not all organizations, however, have applied this methodology successfully (Gijo $\&$ Rao, 2005). Some of them reported that the best way to manage the change is through increased and sustained communication, motivation, and training (Antony, 2004; Brun 2011), which are the issues associated with HRM. The importance of HRM to Six Sigma implementation has been recognized in the literature (e.g., Breyfogle et al., 2001; Lee \& Choi, 2006; Motwani et al., 2004). However, few studies have applied soft computing methods for examining the relationships between HRM and Six Sigma implementation for real-world case studies. This paper investigates the role of HRM practices in Six Sigma implementations. Prior studies have identified three HRM practice's employee involvement, employee training, and employee performance and recognition, which are important in modeling a quality culture and in influencing employees' attitudes toward quality (e.g., Bayo-Moriones \& Bayo-Moriones \& Merino-Dí az de Cerio,2001; Bou \& Beltrán, 2005; Howard \& Foster, 1999; Langbert, 2000).

During the past few years, Iran's Ministry of Industry, Mine and trade (IMIMT) plans to detect a good method for illustrating relationships between Six Sigma implementations and HRM in its supported firms, which enhanced their performance by applying Six Sigma continues improvement toolset in their firms and involved with HRM concepts. Soft computing systems play essential role for representing the relationships based on learning paradigm and experts' suggestions, which is an enrich source of knowledge. They also help decision makers extract the notions among various suggestions, unlike hard computing systems, which are based on optimization notion. In this paper, we use fuzzy cognitive maps (FCM) as a subset of the soft computing systems toolbox, which enables us to provide the strength of relationships between HRM indices and Six Sigma implementation's features.

In this study, we do not intend to get involved with various definitions of HRM, but we intend to infer to critical success factors (CSF) from human resources management perspective, which have influences in achieving prosperity in implementations and increasing performance of companies applied Six Sigma methodology in their continues improvement activities. Using collected questionnaires from 24 manufacturing plants which deployment Six Sigma, this study illustrates the effects of the three quality-oriented HRM practices on the implementations of Six Sigma methodology.

\section{Literature review}

The Six Sigma methodology was born in Motorola and it is strongly oriented to measurement, and in particular to the adoption of statistical techniques. It has been widely used method and it is now encompassed in a comprehensive framework advocating the adoption of some basics quantitative tools for the resolution of the most common problems, which characterize the organizations (Brun 2011). After enounced Six Sigma, many companies have been familiar with total quality management (TQM) and well known it's PDCA cycle (plan, do, control and act). Näslund (2008) showed Six Sigma essentially repackaged version of the TQM and this method seems to follow the fad (product) life cycle. The literature offers similar and rather general CSF for these methods, e.g. top management support and the importance of communication and information and by inspecting a lot of papers he suggested that all CSF were similar in the two mentioned methods.

Many of researchers emphasized on the role of HRM in quality management (QM) activities. $\mathrm{Zu}$ (2009) named some of HRM indices in Six Sigma implementation projects under the name of 
'infrastructure QM', such as 'top management support', 'workforce management' and 'customer relationship' these notions have been adapted from HRM practices.

The notion of 'customer relationship' is associated with Six Sigma projects implementations. It contains both inner-customer and outer-customer and without correct managements systems to manage two mentioned categories where Six Sigma projects cannot achieve its determined objectives (Zu, 2008; Pande \& Holp, 2002; Eckes, 2003).

Brun (2011) statistically showed the frequency of the various CSF, which outs of a sample, contains 18 papers tried to analyze the reasons behind the success of real life applications of Six Sigma, which is depicted in Fig. 1. As we can observe, the HRM related factors for example 'Management involvement', 'Linking six sigma to customer', 'Training' and 'Linking six sigma to human resource', have more frequency in the selected papers and also these notions adapted from HRM practices.

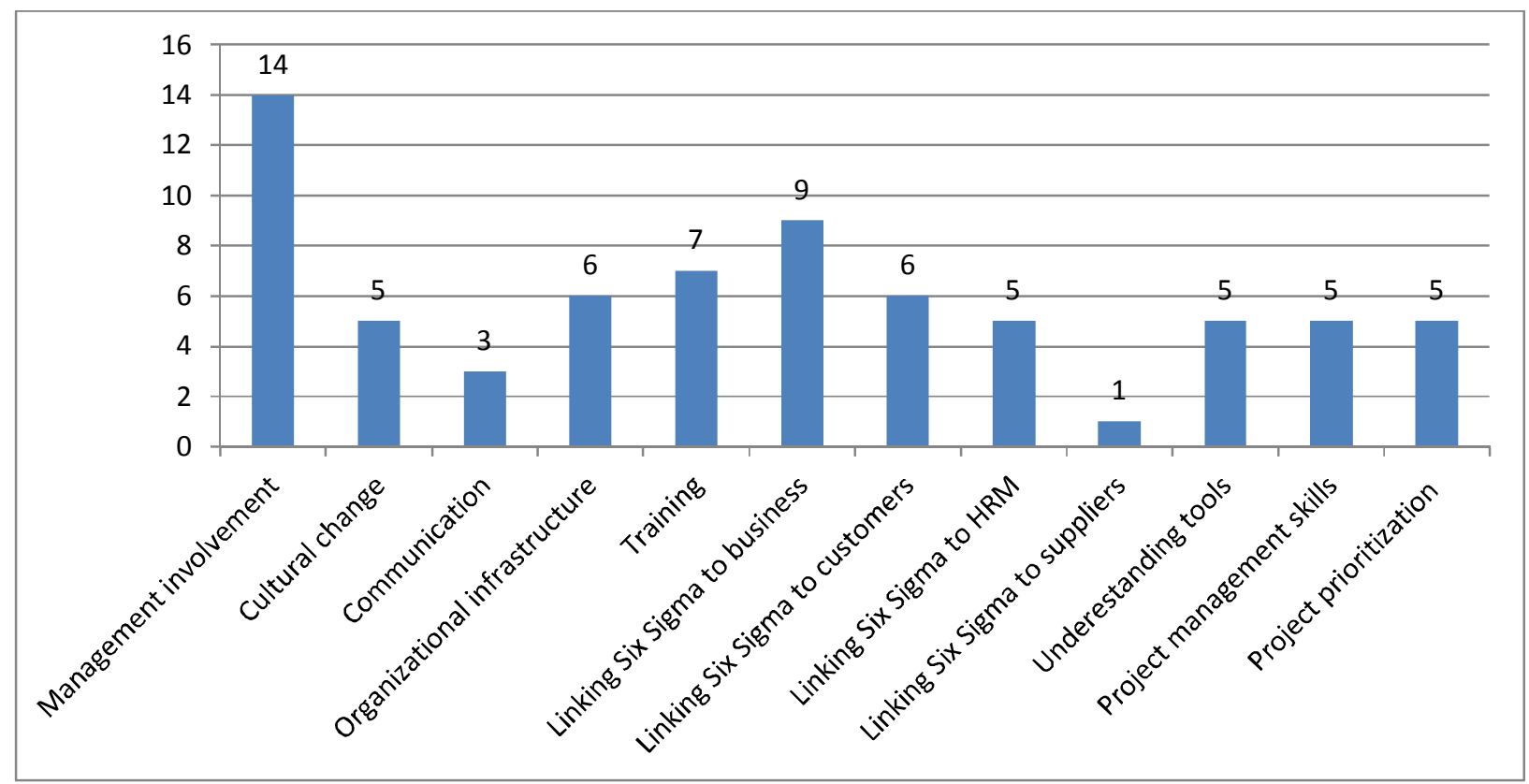

Fig. 1. The frequency of CSF in the literature (Brun, 2011)

In addition, Six Sigma involves with using a comprehensive set of structured procedures named DMAIC, contains define, measure, analyze, improve and control phases. The DMAIC cycle comes into play to meet the customer's needs consistently and perfectly enables us to have continues improvement in our activities (see Fig. 2). The people how's involved in Six Sigma continues improvement projects have different names, such as champion, master black belt (MBB), black belt (BB) and green belt (GB). The mentioned categories for members of Six Sigma improvement teams depends on experience, organizational hierarchy position and training (Pande \& Holp, 2002; Eckes, 2003). Also, HRM is concerned with people and the way they are managed, and is recognized as one of the important sources of competitive advantage (Schuler and MacMillan, 1984). From the resource-based view of the firm, HRM contributes to sustained competitive advantage by facilitating the development of other organizational capabilities (Saá-Pérez \& García-Falcón, 2002). The HRM system supports an organization's QM effort by reinforcing employee relationships and group consciousness of the need for customer satisfaction, raising employee competence, and helping to achieve culture change by involving members in quality decision making (Yang, 2006). 




Fig. 2. DMAIC structured improvement cycle

The existing body of literature examining the relationship of HRM and QM provides a theoretical background to investigate HRM and Six Sigma. Prior studies have examined various HRM dimensions such as human resource planning, recruiting and selection, work design and analysis, training and education, job rotation, leadership development, performance appraisal, incentive compensation, benefits and profit sharing, employee development, employee security and health, communication, and the use of teams (e.g., Dean \& Bowen, 1994; Bayo-Moriones \& Merino-Dí az de Cerio, 2001; Bou \& Beltran, 2005; Flynn et al., 1995; Mayer, 2002; Yang, 2006). Among them, dimensions related to such practices as employee involvement, employee training, and employee performance recognition are suggested to have a particularly important impact on QM implementation (Bayo-Moriones \& Merino-Dí az de Cerio, 2001; Bou \& Beltran, 2005; Flynn et al., 1995; Kaynak, 2003). Enhancing Six Sigma implementation through human resource management employee involvement is necessary for continuous improvement because ultimately people make quality happen (Rahman \& Bullock 2005).

Teamwork and group problem solving are important parts of quality management (QM), which permits decentralized decision making by allowing employees to make decisions on their own (Dean and Bowen 1994; Flynn Schroeder and Sakakibara 1994). Teamwork contributes to employee involvement by creating collaboration between management and employees that allows non managerial employees to make important contributions to quality improvement (Dean \& Bowen, 1994). In addition, cross-functional teams create synergy by involving different functions to achieve the outcomes of the whole organization. Employee training is the cornerstone of QM implementation (Juran, 1993). The QM-related training includes training in small group problem solving, communication, statistical tools, and other relevant areas, in addition to classroom and on-site training about specific tasks, with the purpose of transforming employees into creative problem 
solvers (Flynn et al., 1994; Kaynak, 2003). Through training, employees also can better understand the QM policies implemented by the organization and become more inspired to take part in the quality improvement effort (Joseph, 1999). Employee performance and recognition involves the methods implemented by organizations to provide appropriate compensation, promotion, and recognition policies for their employees. The traditional employee performance appraisal approach emphasizes the impact of individual differences, but the quality-oriented performance appraisal practice requires group performance, quality-based incentives, and compensation based on breadth of skills (Dean \& Bowen, 1994; Flynn et al., 1994). Maintaining an effective quality culture requires recognizing and rewarding continuous quality improvement activities and quality customer services, including both formal and informal, and financial and nonfinancial rewards for individuals and teams that contribute to the quality improvement effort (Blackburn \& Rosen, 1993).

The QM research has shown that the three quality-oriented HRM practices identified previously contribute to quality improvement by helping firms develop a competent, committed work force for continuous improvement (Flynn et al., 1994). Kaynak (2003) found that organizations use quality data better by training their employees in quality tools and by encouraging them to participate in decision-making processes, teamwork, and employee recognition. Similarly, Sila and Ebrahimpour (2005) found that it is critical for designing high-quality products and services and to manage processes for quality that firms build organizational competencies through effective HRM practices and focused on employee training and satisfaction. Nair (2006) conducted a meta-analysis of 26 QM studies and found that people management practices were highly correlated to aggregate business performance, financial performance, and operational performance. In addition, people management significantly interacts with other QM practices to affect customer service and product quality.

\section{Method of Research}

A cognitive map (CM) is a directed digraph for showing causality between concepts in complex foundations, first introduced by Axlord (1976) in political complications.

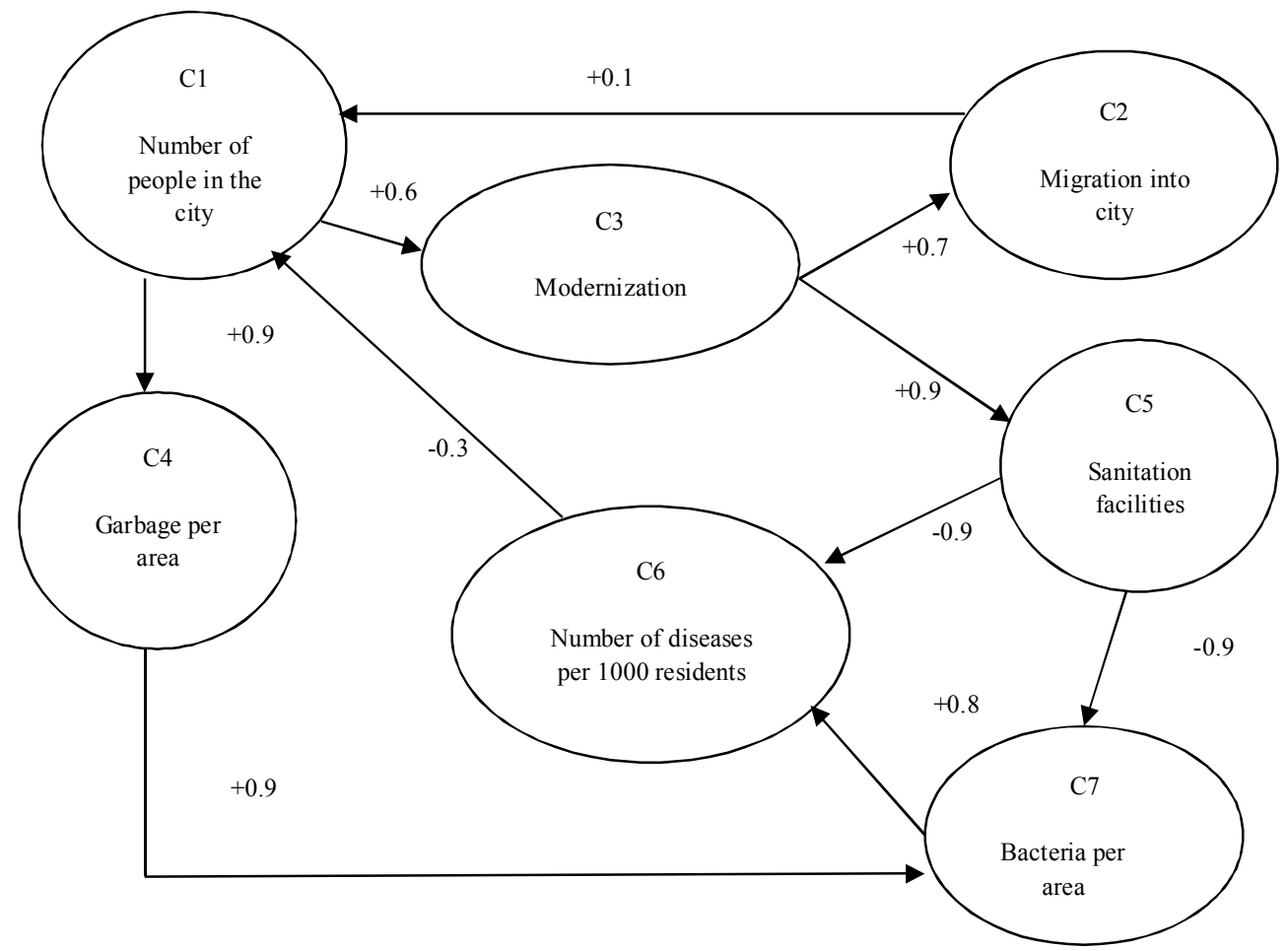

Fig. 3. A classic form of the fuzzy cognitive maps (FCM) 
A fuzzy cognitive Map (FCM) is a graphical representation, consisting of nodes indicating the most relevant factors of a decisional environment; and the links between these nodes representing the relationships between those factors. FCM is a modeling methodology for complex decision systems originated from the combination of fuzzy logic and neural networks. A FCM explains the behavior of a system in terms of concepts; each concept representing an entity, a state, available, or a characteristic of the system. FCMs have been applied in simulation, modeling of organizational strategies, support for strategic problem formulation and decision analysis, knowledge bases construction, managerial problems diagnosis, failure modes effects analysis, requirements analysis, systems requirements specification, urban design support, relationship management in airlines Services and web-mining inference amplification (Rodriguez-Repiso et al., 2007). For making FCM framework for current study we needs define concepts as node, we use $\mathrm{C}_{\mathrm{i}}$ for concept $\mathrm{i}$ (for $\mathrm{i}=1,2, \ldots$, 6) defined as below.

\section{Table 1}

The descriptions of concepts in the proposed fuzzy cognitive map

\begin{tabular}{|c|c|c|c|}
\hline Concept & Abbreviation & Concept & Abbreviation \\
\hline HRM practice concept & & Use of Six Sigma methodology concept & \\
\hline - employee involvement & $\mathrm{C}_{1}$ & Six Sigma structured improvement procedure & $\mathrm{C}_{4}$ \\
\hline - $\quad$ employee training & $\mathrm{C}_{2}$ & - $\quad$ Six Sigma focus on metrics & $\mathrm{C}_{5}$ \\
\hline $\begin{array}{l}\text { - employee performance and } \\
\text { recognition }\end{array}$ & $\mathrm{C}_{3}$ & - Six Sigma role structure concept & $\mathrm{C}_{6}$ \\
\hline
\end{tabular}

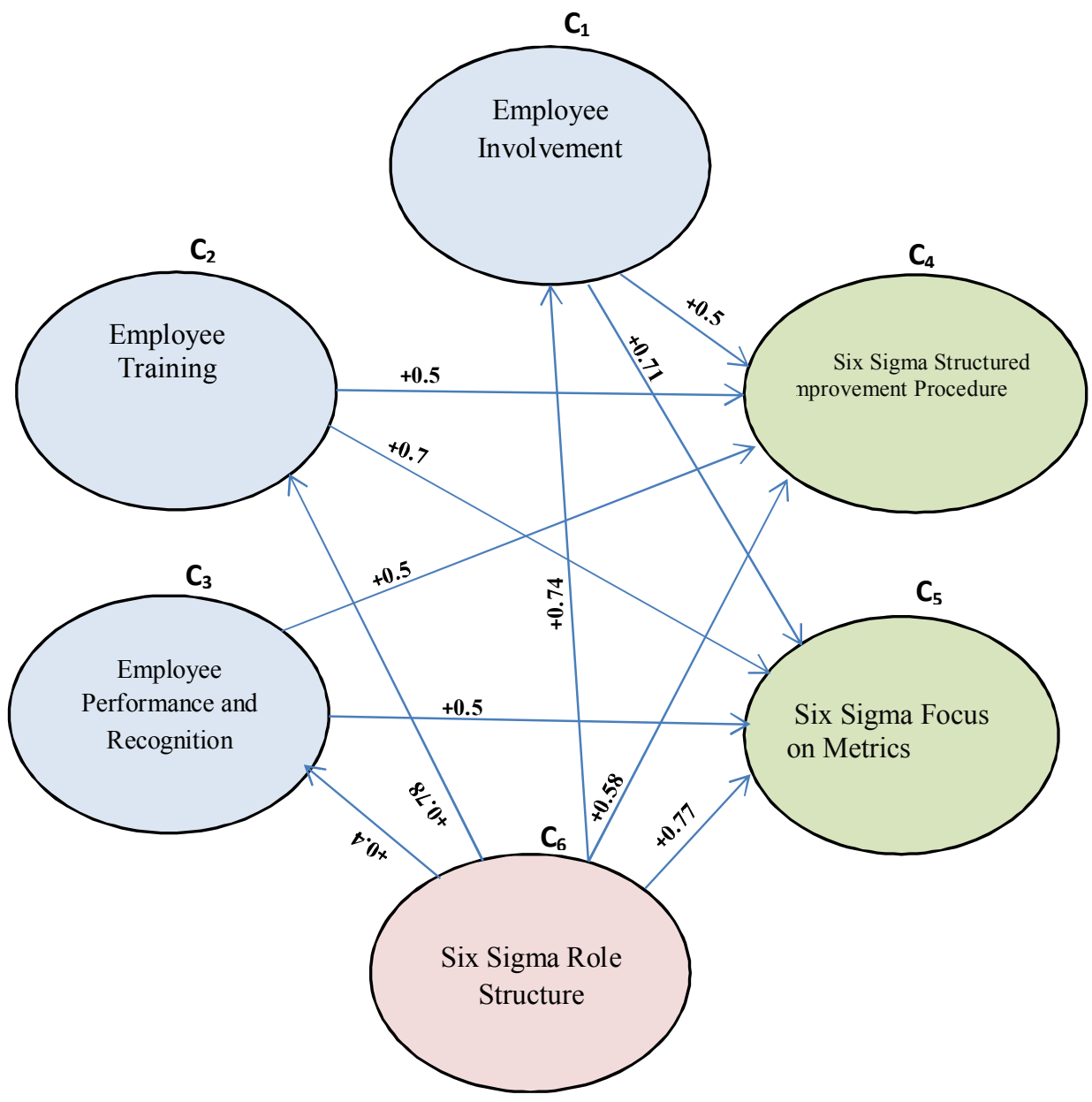

Fig. 4. A sample of relationship in Six Sigma projects implementation 
For determining the strength between two concepts of $i$ and $j$ denoted by $W_{i j}$, we should first define sign of the strength between two concepts. If increase in one concept increases the amount of another concept, we say there is a positive relationship between two concepts. When increase in the amount of one concept decreases the amount of another concept, consequently we say there is a negative relationship between two concepts. If there is not any logical or empirical relationship between two concepts, we conclude there is not any relationship between mentioned concepts. For example, in Six Sigma improvements activities, an increase in the amounts of 'employee training' activities increases 'Six Sigma structured improvement procedure' (see Fig 4), so we conclude there is a positive relationship between 'employee training' and 'Six Sigma structured improvement procedure' (Rodriguez-Repiso et al., 2007; Kosko, 1986).

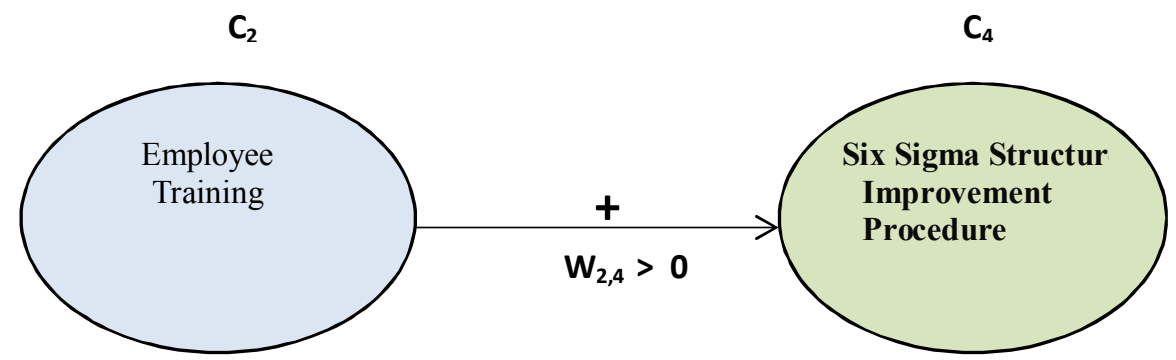

Fig. 4. A sample of relationship in Six Sigma projects implementation

According above mentioned subjects, we concluded amounts of this relationships in FCM can be positive or negative or zero defined as below:

$\left\{\begin{array}{cc}W_{i j}>0 & \text { Positive relationship } \\ W_{i j}<0 & \text { Negative relationship } \\ W_{i j}=0 & \text { No relationship }\end{array}\right.$

For obtaining the amount of these relationships we use Rodriguez-Repiso methodology, which is based on four matrix consist of initial matrix of concepts (IMC), fuzzified matrix of concepts (FMC), strength of relationships matrix of concepts (SRMC) and final matrix of concepts (FMS). In first step, we compose initial matrix of concepts (IMC) by collecting 24 questionnaires, which is prepared by champions of Six Sigma teams from 24 manufacturing plants. In this questionnaire, we asked them to assign how six factors rolled in six sigma projects (see Table 2).

Table 2

Data's collected from 24 manufactory plants (IMC)

\begin{tabular}{ccccccccccccccccccccccccccc}
\hline Plant & $\mathbf{p}_{1}$ & $\mathbf{p}_{2}$ & $\mathbf{p}_{3}$ & $\mathbf{p}_{4}$ & $\mathbf{p}_{5}$ & $\mathbf{p}_{6}$ & $\mathbf{p}_{7}$ & $\mathbf{p}_{\mathbf{8}}$ & $\mathbf{p}_{9}$ & $\mathbf{p}_{10}$ & $\mathbf{p}_{11}$ & $\mathbf{p}_{12}$ & $\mathbf{p}_{13}$ & $\mathbf{p}_{14}$ & $\mathbf{p}_{15}$ & $\mathbf{p}_{16}$ & $\mathbf{p}_{17}$ & $\mathbf{p}_{18}$ & $\mathbf{p}_{19}$ & $\mathbf{p}_{20}$ & $\mathbf{p}_{21}$ & $\mathbf{p}_{22}$ & $\mathbf{p}_{23}$ & $\mathbf{p}_{24}$ \\
\hline $\mathbf{C}_{1}$ & VH & H & M & VH & VH & VH & H & VH & VH & M & H & VH & VH & VH & VH & M & H & H & L & M & VH & VH & VH & VH \\
$\mathbf{C}_{2}$ & VH & H & H & H & H & H & VH & M & H & VH & VH & M & M & VH & H & M & M & M & H & VH & M & M & H & VL \\
$\mathbf{C}_{3}$ & M & L & H & L & L & H & L & L & VL & L & L & L & L & L & VH & VH & H & H & VH & VL & M & H & VH & M \\
$\mathbf{C}_{4}$ & M & H & VH & L & M & L & H & L & H & M & L & H & VH & H & H & VH & H & M & L & H & L & M & L & M \\
$\mathbf{C}_{5}$ & VH & H & H & VH & H & H & M & H & VH & H & VH & M & H & VH & VH & H & M & L & M & VL & M & M & VL & H \\
$\mathbf{C}_{6}$ & H & H & M & VH & VH & VL & H & VH & H & VH & VH & H & H & VH & H & L & M & M & M & H & M & H & M & VH \\
\hline
\end{tabular}

In Table 2, VH means very high influences; $H$ represents high influence; $M$ shows medium influence; $\mathrm{L}$ means very low influences; and VL is used for very low influences. 
Table 3

Fuzzified matrix of concepts (FMC)

\begin{tabular}{|c|c|c|c|c|c|c|c|c|c|c|c|c|}
\hline & $\mathrm{p} 1$ & $\mathrm{p} 2$ & p3 & $\mathrm{p} 4$ & p5 & p6 & p7 & $\mathrm{p} 8$ & p9 & $\mathrm{p} 10$ & p11 & p12 \\
\hline $\mathrm{C} 1$ & 1 & 0.67 & 0.33 & 1 & 1 & 1 & 0.67 & 1 & 1 & 0.33 & 0.67 & 1 \\
\hline $\mathrm{C} 2$ & 1 & 0.75 & 0.75 & 0.75 & 0.75 & 0.75 & 1 & 0.5 & 0.75 & 1 & 1 & 0.5 \\
\hline C3 & 0.5 & 0.25 & 0.75 & 0.25 & 0.25 & 0.75 & 0.25 & 0.25 & 0 & 0.25 & 0.25 & 0.25 \\
\hline $\mathrm{C} 4$ & 0.33 & 0.67 & 1 & 0 & 0.33 & 0 & 0.67 & 0 & 0.67 & 0.33 & 0 & 0.67 \\
\hline C5 & 1 & 0.75 & 0.75 & 1 & 0.75 & 0.75 & 0.5 & 0.75 & 1 & 0.75 & 1 & 0.5 \\
\hline \multirow[t]{2}{*}{ C6 } & 0.75 & 0.75 & 0.5 & 1 & 1 & 0 & 0.75 & 1 & 0.75 & 1 & 1 & 0.75 \\
\hline & $\mathrm{p} 13$ & $\mathrm{p} 14$ & p15 & p16 & $\mathrm{p} 17$ & $\mathrm{p} 18$ & p19 & p20 & $\mathrm{p} 21$ & p22 & p23 & p24 \\
\hline $\mathrm{C} 1$ & 1 & 1 & 1 & 0.33 & 0.67 & 0.67 & 0 & 0.33 & 1 & 1 & 1 & 1 \\
\hline $\mathrm{C} 2$ & 0.5 & 1 & 0.75 & 0.5 & 0.5 & 0.5 & 0.75 & 1 & 0.5 & 0.5 & 0.75 & 0 \\
\hline C3 & 0.25 & 0.25 & 1 & 1 & 0.75 & 0.75 & 1 & 0 & 0.5 & 0.75 & 1 & 0.5 \\
\hline $\mathrm{C} 4$ & 1 & 0.67 & 0.67 & 1 & 0.67 & 0.33 & 0 & 0.67 & 0 & 0.33 & 0 & 0.33 \\
\hline C5 & 0.75 & 1 & 1 & 0.75 & 0.5 & 0.25 & 0.5 & 0 & 0.5 & 0.5 & 0 & 0.75 \\
\hline C6 & 0.75 & 1 & 0.75 & 0.25 & 0.5 & 0.5 & 0.5 & 0.75 & 0.5 & 0.75 & 0.5 & 1 \\
\hline
\end{tabular}

Each elements in row $i$ and column $j$ is opinions of $j^{\text {th }}$ person about $i^{\text {th }}$ concepts denoted by $O_{i, j}$, also we show row $i$ in corresponding matrix with $\mathrm{V}_{\mathrm{i}}$ (Rodriguez-Repiso et al., 2007; Alizadeh et al., 2008). Next, we compose fuzzified matrix of concepts (FMC) by using the data from Table 2, and translates this matrix into a fuzzy matrix by using Likert scale ( $\mathrm{VH}=9, \mathrm{H}=7, \mathrm{M}=5, \mathrm{~L}=3, \mathrm{VL}=1)$ and Eq. (2). Every rows illustrates intense of each concepts by different people contributing in Six Sigma improvements teams (Alizadeh et al., 2008). $\operatorname{Max}\left(\mathrm{O}_{\mathrm{iq}}\right) \Rightarrow \mathrm{Xi}\left(\mathrm{O}_{\mathrm{iq}}\right)=1$ and $\operatorname{Min}\left(\mathrm{O}_{\mathrm{ip}}\right) \Rightarrow \mathrm{Xi}\left(\mathrm{O}_{\mathrm{ip}}\right)=1$; for $\mathrm{p}, \mathrm{q}=1,2,3, \ldots, 24 ; \mathrm{i}=1,2, \ldots, 6$

$\mathrm{X}_{\mathrm{i}}\left(\mathrm{O}_{\mathrm{ij}}\right)=\frac{\mathrm{O}_{\mathrm{iq}}-\operatorname{Min}\left(\mathrm{O}_{\mathrm{ip}}\right)}{\operatorname{Max}\left(\mathrm{O}_{\mathrm{iq}}\right)-\operatorname{Min}\left(\mathrm{O}_{\mathrm{ip}}\right)}$

In some cases similar to this study, it is difficult to assign a certain number (score) for each question between 0 and 100. For facilitating doing this work, we change Rodriguez-Repiso algorithms by using linguistically variables standby numerical scale, without losing main FCM concepts (Rodriguez-Repiso et al., 2007; Kosko, 1986).

In the third step, we need to compute adjacency of two concepts $C_{i}$ and $C_{j}$ by using two kinds of formulations. If two concepts $C_{i}$ and $C_{j}$ have a direct and a positive relationship we use $\mathrm{X}_{1}\left(\mathrm{~V}_{\mathrm{j}}\right)-$ $\mathrm{X}_{2}\left(\mathrm{~V}_{\mathrm{j}}\right)$ for distance between two concepts, otherwise, $\mathrm{f}$ two concepts have reverse relation Bijp, we use $\mathrm{X}_{1}\left(\mathrm{~V}_{\mathrm{j}}\right)-\left(1-\mathrm{X}_{2}\left(\mathrm{~V}_{\mathrm{j}}\right)\right)$. Subsequently, we define two types of formulations to compute distance by using absolute assign for two mentioned formulations: $\left.d_{j}=\mid X_{1}\left(V_{j}\right)-X_{2}\left(V_{j}\right)\right) \mid$ for direct relations and $\mathrm{d}_{\mathrm{j}}=\left|\mathrm{X}_{1}\left(\mathrm{~V}_{\mathrm{j}}\right)-\left(1-\mathrm{X}_{2}\left(\mathrm{~V}_{\mathrm{j}}\right)\right)\right|$ for diverse relationships. According to above subjects another variable should be define as $\mathrm{AD}$ determined as follow,

$\mathrm{AD}=\frac{\sum_{\mathrm{j}=1}^{\mathrm{m}} \mathrm{d} \mathrm{j}}{\mathrm{m}}$

where the adjacency of two concepts rows is defined with $\mathrm{S}$ as $\mathrm{S}=1-\mathrm{AD}$ (4).

Table 4

Strength of relationships matrix of concepts (SRMC)

\begin{tabular}{cccccccc}
\hline Concept & C1 & C2 & C3 & C4 & C5 & C6 \\
\hline C1 & - & $\mathbf{0 . 6 4}$ & $\mathbf{0 . 5 2}$ & $\mathbf{0 . 5 1}$ & $\mathbf{0 . 7 1}$ & $\mathbf{0 . 7 4}$ \\
C2 & 0.64 & - & 0.58 & 0.57 & 0.78 & 0.78 \\
C3 & $\mathbf{0 . 5 2}$ & $\mathbf{0 . 5 8}$ & - & $\mathbf{0 . 5 9}$ & $\mathbf{0 . 5 9}$ & $\mathbf{0 . 4 9}$ \\
C4 & 0.51 & 0.57 & 0.59 & - & 0.60 & 0.58 \\
C5 & $\mathbf{0 . 7 1}$ & $\mathbf{0 . 7 8}$ & $\mathbf{0 . 5 9}$ & $\mathbf{0 . 6 0}$ & - & $\mathbf{0 . 7 7}$ \\
C6 & 0.74 & 0.78 & 0.49 & 0.58 & 0.77 & - \\
\hline
\end{tabular}


Some of computed values between concepts (see Table 4) might be impossible or irreligious in Six Sigma activities and do not existence in empirical activates should be ignored also mathematics computes acquires this deleted relationships. With this work obtained final matrix of concepts (FMS).

\section{Table 5}

Final matrix of concepts (FMS)

\begin{tabular}{ccccccc}
\hline Concept & $\mathrm{C}_{1}$ & $\mathrm{C}_{2}$ & $\mathrm{C}_{3}$ & $\mathrm{C}_{4}$ & $\mathrm{C}_{5}$ & $\mathrm{C}_{6}$ \\
\hline $\mathrm{C}_{1}$ & - & - & - & 0.51 & 0.71 & - \\
$\mathrm{C}_{2}$ & - & - & - & 0.57 & 0.78 & - \\
$\mathrm{C}_{3}$ & - & - & - & 0.59 & 0.59 & - \\
$\mathrm{C}_{4}$ & - & - & - & - & - & - \\
$\mathrm{C}_{5}$ & - & - & - & - & - & - \\
$\mathrm{C}_{6}$ & 0.74 & 0.78 & 0.49 & 0.58 & 0.77 & - \\
\hline
\end{tabular}

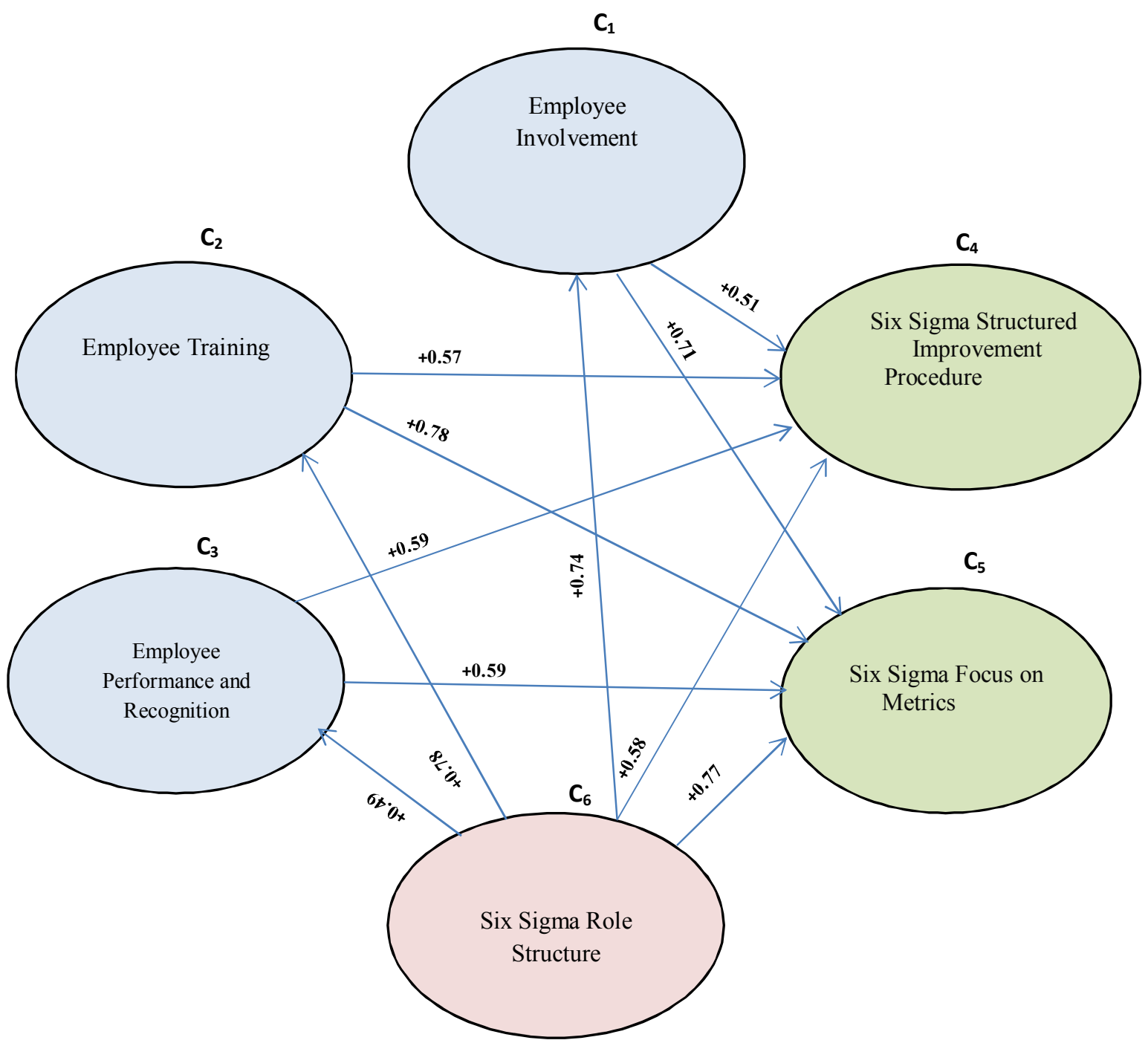

Fig. 5. A fuzzy cognitive map of impacts between HRM and Six Sigma 


\section{Conclusions}

In this paper, we have presented an empirical investigation to illustrate the intense of relationships between the human resources management indices and Six Sigma project implementation indices in some selected Iranian manufacturing firms. By using the fuzzy cognitive maps (FCM), we were able to show the strength of relationships among various indices. This study helps quality and human resource managers learn how to manage the critical indices to achieve their determined goals and to increase Six Sigma project performance throw human resource management perspective. According to the results of this survey, the maximum correlation is between 'Employee Training- Six Sigma Focus on Metrics' and 'Six Sigma Role Structure-Employee Training'.

\section{Acknowledgement}

The authors would like to thank the anonymous referees for constructive comments on earlier version of this paper.

\section{References}

Alizadeh, S., Ghazanfari, M., Jafari, M., \& Hooshmand, S. (2007). Learning FCM by Tabu Search. International Journal of Computer Science, 2(2), 142- 149

Antony, J., \& Banuelas, R. (2002). Key ingredients for the effective implementation of Six Sigma program. Measuring Business Excellence, 6(4), 20-27.

Antony, J. (2004). Some pros and cons of Six Sigma: an academic perspective. The TQM Magazine, 16(4), 303-306.

Armstrong, M. (2003). A handbook of human resource management practice. Kogan Page Limited.

Axelrod, R. (1976). Structure of decision: the cognitive maps of politicalelites. New Jersey: Princeton, Princeton University Press.

Bayo-Moriones, A., \& Merino-Dí az de Cerio, J. (2001).Quality management and high performance work practices: Do they coexist?. International Journal of Production Economics, 73(3), 251-259.

Blackburn, R., \& Rosen, B. (1993). Total quality and human resources management: lessons learned from Baldrige award-winning companies. The Academy of Management Executive, 7(3), 49-66.

Bou, J. C., \& Beltrán, I. (2005). Total quality management, high-commitment human resource strategy and firm performance: an empirical study. Total Quality Management \& Business Excellence, 16(1), 71-86.

Breyfogle, F., Cupello, J., \& Meadows, B. (2001). Managing six sigma. New York: John Wiley \& Sons.

Brue, G., \& Launsby, R. (2003). Design for Six Sigma. New York: McGraw-Hill.

Brun, A. (2011). Critical success factors of six sigma implementations in Italian companies. International Journal of Production Economics, 131, 158- 164.

Eckes, G. (2003). Six Sigma Team Dynamics. New York: John Wiley \& Sons.

Dean, H. W., \& Bowen, D. E. (1994). Management theory and total quality: Improving research and practice through theory development. Academy of Management Review, 19 (3), 392- 418.

Flynn, B. B. (1994). The relationship between quality management practices, infrastructure and fast product innovation. Benchmarking for Quality Management \& Technology, 1(1), 48-64.

Flynn, B. B., Schroeder, R. G., \& Sakakibara, S. (1994). A framework for quality management research and an associated measurement instrument. Journal of Operations management, 11(4), 339-366.

Flynn, B. B., Schroeder, R. G., \& Sakakibara, S. (1995). The impact of quality management practices on performance and competitive advantage. Decision Sciences, 26(5), 659-691.

Foster, S. T. J. (2007). Does six sigma improve performance?. Quality Management Journal, 14(4), $1-20$. 
Gijo, E. V., \& Roo, T. (2005). Six sigma implementation hurdles and more hurdles. Total Quality Management, 16(6), 721-725.

Harry, M., \& Schroeder, R. G. (2000). Six Sigma: The breakthrough management strategy revolutionizing the world's top corporations. New York: Doubleday publishers.

Howard, 1. W., \& Foster, S. T. (1999). The influence of human resource practices on empowerment and employee perceptions of management commitment to quality. Journal of Quality Management, 4 (1), 5- 22.

Joseph, I. N. (1999). An instrument for measuring total quality management implementation in manufacturing based business units in India. International Journal of Production Research 37, $2201-2215$.

Juran, J. M. (1993). Made in the USA: A renaissance in quality. Harvard Business Review, 71(4), 4250 .

Kosko, B. (1986). Fuzzy cognitive maps. International Journal on Man-Machine Studies, 2, 65- 75.

Kandasamy, V., \& Smarandache, F. (2004). Fuzzy cognitive maps and Neutrosophic cognitive maps. Phoenix, (15th September 2013). Available at: http://www.gallup.unm.edu.

Kardaras, D., \& Karakostas, B. (1999). The use of fuzzy cognitive maps to simulate the information systems strategic planning process. Information and Software Technology, 41(4), 197-210.

Kaynak, H. (2003). The relationship between total quality management practices and their effects on firm performance. Journal of operations management, 21(4), 405-435.

Langbert, M. (2000). Human resource management and Deming's continuous improvement concept. Journal of quality management, 5(1), 85-101.

Lee, K. C., \& Choi, B. (2006). Six Sigma management activities and their influence on corporate competitiveness. Total Quality Management \& Business Excellence, 17(7), 893-911.

Mayer, K. J. (2002). Human resource practices and service quality in theme parks. International Journal of Contemporary Hospitality Management, 14(4), 169-175.

Motwani, J., Kumar, A., \& Antony, J. (2004). A business process change framework for examining the implementation of Six Sigma: a case study of Dow Chemicals. The TQM Magazine, 16(4), 273-283

Nair, A. (2006). Meta-analysis of the relationship between quality management practices and firm performance-implications for quality management theory development. Journal of Operations Management, 24(6), 948-975.

Näslund, D. (2008). Lean, six sigma and lean sigma: fads or real process improvement methods?. Business Process Management Journal, 14(3), 269-287.

Pande, P., \& Holp, L. (2002). What is Six Sigma? . New York: McGraw-Hill.

Neuman, R. P., \& Cavanagh, R. (2000). The six sigma way: How GE, Motorola, and other top companies are honing their performance. McGraw Hill Professional.

Rahman, S. U., \& Bullock, P. (2005). Soft TQM, hard TQM, and organisational performance relationships: an empirical investigation. Omega, 33(1), 73-83.

Rodriguez-Repiso, L., Setchi, R., \& Salmeron, J. L. (2007). Modelling IT projects success with fuzzy cognitive maps. Expert Systems with Applications,32(2), 543-559.

Saá-Pérez, P. D., \& García-Falcón, J. M. (2002). A resource-based view of human resource management and organizational capabilities development.International Journal of Human Resource Management, 13(1), 123-140.

Schuler, R. S., \& MacMillan, I. C. (1984). Gaining competitive advantage through human resource management practices. Human Resource Management, 23(3), 241-255.

Sila, I., \& Ebrahimpour, M. (2005). Critical linkages among TQM factors and business results. International journal of operations \& production management,25(11), 1123-1155.

Snee, R. D. (1999). Why Should Statisticians Pay Attention to Six Sigma?: an examination for their role in the six sigma methodology. Quality Progress, 32(9), 100-103.

Storey, J. (1989). From personnel management to human resource management. London: Routledge. 
Yang, C. C. (2006). The impact of human resource management practices on the implementation of total quality management: An empirical study on high-tech firms. The TQM Magazine, 18(2), 162173.

$\mathrm{Zu}, \mathrm{X}$. (2009). Infrastructure and core quality management practices: How do they affect quality?. International Journal of Quality \& Reliability Management, 26(2), 129 - 149. 